\title{
Cooperativas e representação política empresarial no Brasil: o caso do cooperativismo rural no Paraná
}

\author{
Paulo Roberto Neves Costa ${ }^{1}$ \\ Paulo Roberto Stöberl ${ }^{2}$
}

\section{Resumo}

Este artigo analisa a gênese da institucionalização da ação política do cooperativismo rural no Paraná com o intuito de estudá-lo enquanto uma das formas de representação política empresarial no Brasil. Utilizando documentos e entrevistas, a pesquisa contemplou o período de 1907 à criação da OCEPAR (Sindicato e Organização das Cooperativas do Estado do Paraná) em 1971, uma das mais importantes entidades representativas do cooperativismo no Brasil. Tal estudo se mostrou importante para a análise da relação entre cooperativismo e interesses empresariais no Brasil e em particular no Paraná, e dos fatores que ainda hoje influenciam a sua ação política. Constatamos as particularidades históricas e legais do cooperativismo no Brasile a necessidade de construir categorias analíticas que dêem conta da complexidade de sua dimensão empresarial, as cooperativas empresariais.

Palavras-chave: empresariado; cooperativas empresariais; cooperativismo rural; representação política empresarial; OCEPAR; Paraná.

\section{Introdução}

Ao estudar as cooperativas e as entidades a ela relacionadas encontramos expressões tentando aglutinar diversos elementos e conceitos, por exemplo, movimento cooperativista ou mesmo setor cooperativo. Tais designações também abrangem o complexo conjunto formado pelas sociedades cooperativas, a doutrina e a filosofia cooperativista, além dos cooperados e sua representação, quer sindical

\footnotetext{
1 Professor do Programa de Pós-Graduação em Ciência Política da Universidade Federal do Paraná, co-editor da Revista de Sociologia e Política, coordenador do Núcleo de Pesquisa em Sociologia Política Brasileira-UFPR e bolsista produtividade do CNPq. E-mail: paulocostaufpr@gmail.com.

2 Doutorando do Programa de Pós-Graduação em Ciência Política da Universidade Federal do Paraná e pesquisador do Núcleo de Pesquisa em Sociologia Política Brasileira-UFPR.E-mail: pstoberl@uol.com.br.
} 
quer organizacional ${ }^{3}$. A arquitetura legal do sistema de representação do cooperativismo resultou na criação de uma organização que congrega as cooperativas em cada estado. Este sistema institui de forma compulsória o registro das cooperativas a esta organização, e consequentemente sua representação formal, mediante uma contribuição anual, dando às cooperativas o direito de obter serviços. A natureza jurídica dessas organizações representativas é de "sociedades civis" com poder legal de exercer a função de órgão técnico-consultivo do governo ${ }^{4}$.

Ao analisarmos as sociedades cooperativas, sua estrutura legal e principiológica, notamos que se destinam não só a atuar na esfera da atividade econômica dos associados, mas também na representação política destes. Esta é uma particularidade que sempre existiu no Brasil, daí a dificuldade da lei em defini-las. A legislação de 1903 estabelecia como uma das finalidades do sindicato rural organizar-se como cooperativa, para comercializar a produção de seus filiados 5 .

Por sua vez, um breve percurso pela literatura sobre o cooperativismo no Brasil mostra que há estudos voltados para a relação entre cooperativismo e trabalhadores (NUNES, 2001 e STADUTO et al., 2004) e economia solidária (SINGER, 2001 e LAVILLE, 2001). Outros trabalhos enfocam os problemas das relações entre dirigentes e associados diante dos desafios colocados pelo mercado e buscam propor soluções para tais problemas (SIMIONI et al., 2009; MERIGHI et al., 2013; SOUZA et al., 2011). Há também estudos sobre a

\footnotetext{
${ }^{3}$ Na literatura sobre o assunto há o entendimento de que o cooperativismo não se reduz ao conjunto formado pelas sociedades cooperativas, ou seja, contempla também os cooperados, a entidade representativa e sindical e o serviço social do cooperativismo (SESCOOP) (BOECHE, 2005, p. 33). Também encontramos para o vocábulo cooperativismo a acepção de conjunto de princípios norteadores e configuradores da sociedade (pessoa jurídica) de tal forma a compor uma filosofia. Assim, o vocábulo doutrina é diferente de filosofia, a qual se refere ao ideário de igualdade e alternativa ao capitalismo (CARNEIRO, 1983, p. 15-20; FERNANDEZ, 1968, p. 178-209; LAIDLAW, 1980). Denomina-se "doutrina cooperativista" o conjunto de princípios que moldam as características das sociedades cooperativas no mundo. Estes princípios têm por guardião um organismo supranacional criado em 1895 com sede na Bélgica a ACI - Aliança Cooperativa Internacional (ICA), responsável pela guarda e difusão dos princípios e da filosofia da cooperação societária.

4 Existe uma organização nacional, a Organização das Cooperativas Brasileiras (OCB), composta pelas 27 organizações estaduais. Ver Artigos 105, 107 e 109 da Lei Federal № 5.764/71.

50 Artigo 9o do Decreto Legislativo no 979 de 06 de janeiro de 1903 estabelecia como uma das funções do sindicato agrícola a comercialização da produção dos sindicalizados. Por sua vez, o Artigo 10 possibilitava que o sindicato adotasse a forma de cooperativa.
} 
relação entre cooperativas de consultores que atuam junto às pequenas e médias empresas (DONADONE, et al. 2012). Além disso, há o enfoque do cooperativismo em estudos sobre o patronato e o cooperativismo rural (MENDONÇA, 2010). Por fim, em relação ao caso do Paraná, é possível encontrar análises sobre a diversificação e a importância das cooperativas na economia do estado em período mais recente, que constatam que elas enfrentam questões típicas de "empresas nãocooperativas" (RODRIGUES e GUILHOTO, 2004).

Ao considerarmos as cooperativas rurais ${ }^{6}$ do Paraná verificamos que de, um lado, ocorreu a constituição de agentes com grande relevância econômica ${ }^{7}$. 0 conjunto das cooperativas agropecuárias do Paraná é responsável por $56 \%$ do PIB agropecuário do Paraná, com faturamento de trinta e oito bilhões de reais em 2013 (IPARDES, 1974; OCEPAR, 2013). Isso se deu a despeito do pressuposto do cooperativismo ser a união de pequenas e médias economias como forma de sobreviver no mercado (FRANKE, 1973, p. 1) ${ }^{8}$.

E, de outro lado, este grande crescimento tornou o Paraná uma referência em cooperativismo a partir dos anos 1980. Considerando o elemento econômico como indicativo, observamos que o grupo das cooperativas rurais do Paraná se tornou maior e mais homogêneo do que em São Paulo. No Paraná existem mais de dez cooperativas com faturamento superior a 1 bilhão de reais/ano (OCEPAR, 2013, p. 148-150). E há estimativas de que o Paraná possui $15 \%$ do faturamento do cooperativismo agropecuário brasileiro enquanto São Paulo possuiria uma participação de 8\%, em $2013^{9}$.

Neste trabalho, pretendemos estudar o que estamos chamando de cooperativismo empresarial. Este assunto já foi tratado por diversos trabalhos com diversos objetivos e preocupações distintas

6 Utilizamos o vocábulo rural como sinônimo de agropecuária e não como designação de não urbana.

7 Convém reafirmar que, neste trabalho, não pretendemos fazer uma análise das ações das cooperativas, nem nos aprofundarmos nas características do contexto econômico, social ou político do país ou do Paraná em particular.

8 Segundo Franke, a palavra "cooperativismo" pode ser tomada em duas acepções. Por um lado, designa o sistema de organização econômica que visa eliminar os desajustamentos sociais oriundos dos excessos de intermediação capitalista.Por outro, significa a doutrinacorporificada no conjunto de princípios que devem reger o comportamento do homem integrado naquele sistema (FRANKE, 1971).

${ }^{9}$ Estas informações foram retiradas de bancos de dados econômicos da OCEPAR, da OCESP e da OCB. 
da nossa ${ }^{10}$. Neste texto, a expressão empresarial não está sendo usada no sentido jurídico do termo (sociedade empresária). Também não pretendemos alterar ou questionar a validade e a pertinência do conjunto de princípios formadores da doutrina do cooperativismo. A utilização que fazemos das expressões empresarial, empresário, lógica empresarial e cooperativismo empresarial é um procedimento metodológico sociológico e refere-se unicamente ao fato de que as cooperativas que estamos analisando têm aspectos semelhantes a um empreendimento econômico complexo e de grande porte ${ }^{11}$. Embora não pretendamos discutir todas implicações gerenciais e administrativas deste tipo de cooperativismo, há que se reconhecer que algumas cooperativas agem no mercado em iguais condições de concorrência com outros empreendimentos econômicos, tais como as sociedades anônimas e as sociedades limitadas. As cooperativas não têm como objetivo o lucro ${ }^{12}$. Todavia, buscam obter resultado positivo nas suas operações com o mercado para repassar aos cooperados. Em suma, o cooperativismo empresarial que estamos analisando obedece à estrutura do cooperativismo (doutrina e filosofia), mas assume formas gerenciais e características típicas de "empresas". Trata-se de uma categoria analítica que busca dar conta de um fenômeno bastante particular, ainda pouco estudado.

Por sua vez, aimportância da ação política organizada formada pelo conjunto dos dirigentes das sociedades cooperativas torna-se cada vez mais evidente. No Paraná, issopode ser confirmado pela quantidade de matérias e citações públicas sobre a OCEPAR. Além disso, esta entidade compõe o chamado G7, grupo de entidades de representação das categorias econômicas que existe mesmo sem nenhum acordo formal ou legal que o sustente, do qual a OCEPAR passou a exercer a coordenação em 201413 .

10 Já há algum tempo, foram produzidos trabalhos sobre o cooperativismo enquanto empresa e suas implicações econômicas e sociais (BENETTI, 1992; CORADINI e FREDERICQ, 2009; BEN e SCHLOSSER, 2012; BELUSSO, 2007).

11 Segundo Sonia Mendonça, alguns fatores indicavam a importância das cooperativas agrícolas em meados dos anos 1980: 1- faturamento líquido médio de quase US\$17 milhões, em muito ultrapassando a média do setor agropecuário; 2- em 1985, participação de $84 \%$ nas exportações de trigo, $46 \%$ nas de soja, $69 \%$ nas de leite e $25 \%$ nas de arroz. As cooperativas, conclui a autora, “... comumente associadas a organizações 'não-capitalistas', atingiram desempenho muitas vezes superior ao das empresas francamente capitalistas" (MENDONÇA, 2010, p. 77).

12 Isso está expresso do artigo 4o da Lei Federal no 5.764/71.

13 No Paraná existe um grupo informal de entidades de representação empresarial identificado como $G 7$ que se reúne para discutir assuntos relacionados ao setor produtivo paranaense, como infraestrutura e tributação, junto ao governo estadual e federal. Tal grupo é composto por Ocepar, Faciap (Federação das Associações 
Como veremos a seguir, a confusão de conceitos e a tentativa de conciliação do elemento societário (econômico) com o elemento representativo (sindicato) foram reproduzidas na primeira legislação específica sobre cooperativas, o Decreto no 1.637 de 5 de janeiro de 1907, tanto que seu texto em parte regulava o sindicato rural e em parte regulava a cooperativa. Por este motivo, o período contemplado por nossa pesquisa vai do surgimento desta lei (marco legal) até 1971, quando da constituição da atual entidade de representação do setor cooperativista paranaense, a OCEPAR - Sindicato e Organização das Cooperativas do Estado do Paraná. Criada pela Lei Federal no 5.764/71, originalmente a OCEPAR não tinha função sindical propriamente dita, embora tivesse poder de representação política das cooperativas. A função sindical patronal só passa a existir em 2007.

Considerando o acima exposto, este artigo se propõe a analisar o processo de institucionalização da ação política do cooperativismo agropecuário do Paraná, enquanto representante de agentes econômicos importantes e um espaço de atuação política empresarial. A pesquisa realizou-se através da análise da legislação pertinente, de documentos históricos, principalmente periódicos, ofícios e memorandos internos das extintas entidades de representação nacional e estadual, além de recorrer à literatura e estudos técnicoeconômicos sobre o cooperativismo paranaense, bem como entrevistas com atores que vivenciaram fatos relevantes.

A seguir, analisamos o processo de institucionalização da ação política do cooperativismo no Brasil e no Paraná, e o processo de surgimento e transformação da entidade de representação política do cooperativismo paranaense, que culmina com a criação da OCEPAR. Por fim, apresentamos nossas considerações finais.

Comerciais e Empresariais do Paraná), Faep (Federação da Agricultura do Estado do Paraná), Fecomércio (Federação do Comércio do Paraná), Fiep (Federação das Indústrias do Paraná), Fetranspar (Federação dos Transportes do Paraná) e ACP (Associação Comercial do Paraná). Além disso, tais entidades alternam o comando do Conselho de Administração do SEBRAE no Paraná, sendo que em 2014 a presidência do SEBRAE está com a OCEPAR. O G7 tem não apenas ações reativas, mas também propositivas em âmbito estadual e se mobilizou em torno da criação do Conselho de Desenvolvimento do Paraná e da proposta de auditoria sobre as empresas de pedágio e tem tido atuação importante no debate sobre o reajuste anual do salário mínimo regional. 


\section{A origem da ação e da representação política do cooperativismo.}

Análise do surgimento da ação política institucionalizada do cooperativismo agropecuário no Paraná se dá a partir de três períodos. O primeiro vai de 1907 até 1941 e se refere ao marco legal que instituiu o controle estatal sobre o cooperativismo ${ }^{14}$. 0 segundo período vai de 1941 até 1956 quando se deu a criação da entidade de representação nacional. E o terceiro, entre 1956 e 1971, que culmina com o surgimento da OCEPAR.

A primeira fase do cooperativismo paranaense (1907-1941) é marcada por uma concentração de cooperativas de erva mate, no sul do Paraná (ARAÚJO, 1980) ${ }^{15}$, uma ou outra manifestação de cooperativismo de subsistência, e o início das cooperativas ligadas a colônias de imigrantes ${ }^{16}$. Esta realidade nos induz, quer pela quantidade, quer pela expressão humana e econômica próxima ao irrelevante, a desconsiderar a existência de representatividade política organizada neste período. Uma única exceção pode ser feita ao setor de erva mate, que possuía em 1939 uma cooperativa de segundo grau (federação), com sede em Curitiba (ARAÚJO, 1980: 63)17. Todavia, isso se deu ainda sob a forma dos "consórcios profissionais"18.

Outro fator que nos leva a desconsiderar a importância deste primeiro período no que tange à ação política organizada se funda na confusão de conceitos legais e da regulação brasileira sobre as cooperativas e os sindicatos que vai até o final dos anos 1930. Autores

\footnotetext{
14 Decreto no 6.980 de 12 de março de 1941, que regulamentou o controle estatal sobre o cooperativismo, que foi instituído pelo Decreto-lei no 581 de 1938.

15 Silvia Maria Pereira de Araújo realizou uma importante pesquisa na qual tratou do surgimento formal das sociedades cooperativas no Paraná, registradas na Junta Comercial de 1916 a 1976. Ver ARAÚJO, 1980, em especial, o mapa da p. 64, no qual se localizam as 18 cooperativas de mate.

16 No ano de 1925, foi criada a "Sociedade Cooperativa Hollandeza de Laticínios" mais tarde, Cooperativa Agropecuária Batavo (KIEWIRT, 2011:285).

17 “No Paraná durante os anos de 1935 e 1936 multiplicaram-se os consórcios profissionais, sobretudo os de produtores de mate. Sofreram uma série de pressões até transformarem-se em cooperativas, por volta de 1939." (ARAÚJ0, 1980, p.63).

18 Consórcios profissionais-cooperativos eram uma espécie de sindicatos de "profissionaes de profissões similares ou connexas, inclusive as profissões liberaes", entenda-se não patronal, e também sindicatos agrícolas (constituído de produtores rurais) com fins de representação destes grupos. De 1907 (Decreto no 1.637) até 1938 (Decreto $\mathrm{n}^{\mathrm{o}}$ 581) o Estado confundia cooperativas com sindicato, principalmente o sindicato agrícola (Decreto no 979 de 1903). A partir do Decreto $\mathrm{n}^{\circ}$ 23.611 de 1932 só se poderia criar cooperativas se se tivesse antes um consórcio de pessoas para representá-las, uma espécie de sindicato com finalidade única.
} 
contemporâneos a este período, ao comentar as legislações regulamentadoras das cooperativas, mencionam esta confusão acerca das cooperativas e dos sindicatos, que eram regulados pelo mesmo diploma legal, o Decreto no 1.637 de 1907 (LUZ, 1962 e BULGARELLI, 1965). Após com o Decreto no 22.239 de 1932, foi desfeita a confusão, mas apenas com o Decreto-lei no 581 de 1938, foi sedimentado o conceito de cooperativismo, pois ainda na década de 1930 se exigia a constituição dos "consórcios profissionais" para depois, a partir deles, formarem-se as cooperativas ${ }^{19}$.

Outro dado que pode ser relevante é a natureza autoritária do Estado Novo, dado que não há informações de qualquer iniciativa para uma organização nacional ou mesmo estadual no sentido de uma representação das cooperativas e das pessoas envolvidas no cooperativismo até a década de 1950. E mesmo que insistíssemos em uma análise mais apurada das cooperativas desta época, nos depararíamos com um movimento sindical rural existente. Neste período, o sindicato tinha poderes legais para atuar como cooperativa, comercializando a produção de seus sindicalizados. Enfim, uma entidade se confundia com a outra e, por conseguinte, não é possível separar o sindicalismo do cooperativismo, incorrendo ou em erro na contagem de representação ou de comercialização.

Assim, um primeiro fato relevante no estudo do cooperativismo é esta aparente confusão na definição de papéis, pois, embora simultâneo ao processo de constituição da legislação sindical que vai marcar profundamente não apenas o sindicalismo de trabalhadores como também o de patrões, encontramos a regulação deste ente "cooperativa" de forma apartada. A legislação sobre as cooperativas não distinguia patrões de empregados, e ainda confundia, de um lado, indivíduos e empresas, e, de outro, atividades econômicas e atividade de representação.

${ }^{19}$ Ao se estudar o Direito Cooperativo no período de 1932 até 1938 encontra-se críticas de juristas sobre a confusão de legislações e regulamentações que confundiam os institutos do sindicato com a cooperativa. Nota-se que o Estado ainda não tinha resolvido a questão da conceituação das cooperativas ora atribuindo-lhes a natureza pura de "empresas" ora considerando sua condição de representante dos cooperados, condição que se assemelhava aos sindicatos. Um exemplo desta confusão é o texto do Dec. 23.611 de 1933que instituiu uma figura jurídica semelhante a um sindicato como pré-requisito para constituição das cooperativas. Os "consórcios-profissionais-cooperativos" resgatavam a ideia dos sindicatos agrícolas da legislação de 1903. Este agrupamento organizado de pessoas representadas deveria pré-existir para possibilitar a constituição da cooperativa. Era um sindicato que se transformava em cooperativa, em um segundo momento. Para detalhes ver obra de LUZ, 1962 e o texto do próprio decreto. 
Aqui cabe fazermos uma especulação sobre esta questão. A cooperativa é uma sociedade que visa congregar um maior número de associados, se comparada com outras formas societárias como as sociedades empresárias, justamente para se terganho de escala ${ }^{20}$. 0 agrupamento de pessoas que se uniram sob a forma de cooperativa entre 1903 e1941 foi confundido com o sindicalismo e mesmo na década de 1930 se tentou criar uma espécie de sindicato especial (consórcios profissionais-cooperativos). 0 Estado não soube regular a questão, mas manteve as cooperativas sob sua pesada guarda. A tutela no cooperativismo durou cinqüenta anos, ou seja, de 1938 até $1988^{21}$. A cooperativa possui entre as suas particularidades a de congregar um grande número de pessoas, o fato de a filosofia cooperativista buscar facilitar a atividade econômica do cooperado ao afastar o atravessador, e a natureza diversificada do cooperado ${ }^{22}$. Isso tudo cria um liame de defesa e de representação natural dos envolvidos, fato que distingue as cooperativas das outras empresase lhe dá condições e características próprias.

Por fim, em relação ao período de 1907 a 1941, não é possível separar os produtores rurais cooperados dos não cooperados, haja vista a inexistência de registros dos cooperados. Além disso, a predominância no Paraná de uma agricultura de subsistência neste período implicava em pequenas e médias atividades econômicas, a respeitodas quais não há registros nem dados (IPARDES, 1974) 23.

Em relação ao período de 1941 a 1956, o primeiro indício da possibilidade de uma ação política relevante foi a constituição da "Federação Interestadual das Sociedades Cooperativas de Profissionais de Produção de Mate do Brasil”, AGROMATE, com sede em Curitiba, em cuja base encontravam-se dezoito cooperativas singulares dela formadoras (ARAÚJO, 1980, p. 63-65).

20 Além do que já foi mencionado acima, para exemplificar o tamanho das cooperativas, podemos mencionar alguns dados acerca do número de cooperados em 2013: COAMO - 26.276; C VALE - 14.614; COCAMAR - 11.732; LAR - 9.202; INTEGRADA - 7.429; COCARI - 6404; COASUL - 6.177 (OCEPAR, 2013).

21 Ver inciso XVIII do art. 5 da Constituição Federal.

22 No cooperativismo o cooperado detém tríplice natureza: proprietário (sócio acionista), usuário (utiliza-se da sociedade para alavancar sua atividade econômica, não é investidor é usuário) e fornecedor (fornece a matéria prima para a comercialização ou industrialização). Ver FRANK, 1973 e BULGARELLI, 1998.

$23 \mathrm{Em}$ um estudo do IPARDES foram coletados dados no Departamento de Assistência ao Cooperativismo (DAC), cujos "Boletins Informativos" circularam entre 1948 e 1969, (IPARDES, 1974). Dados mais antigos foram extraídos deestudos econômicos regionais ligados a determinadas culturas, mas sem maiores referências ao cooperativismo (IPARDES, 1974: cap. I). 
Segundo Sílvia Araújo, esta manifestação da representação do setor de erva mate era fruto e reflexo do declínio do setor ervateiro e de suas etapas de comercialização, o que incentivou o agrupamento de agricultores a se organizar sob a forma cooperativa ${ }^{24}$. Em entrevista com David Thiessen25, obtivemos a informação de que a AGROMATE concentrava suas preocupações e ações voltadas aos problemas específicos da cultura ervateira. Sobre as preocupações do setor de mate em relação à política, Thiessen afirmou que as ações se restringiam quase exclusivamente àquelas atreladas à atividade econômica, segundo ele, distintas do que viria a ser feito pela UCEPAR União das Cooperativas Paranaenses (1965-1971) no final da década de 1960, que possuía um caráter mais amplo. Mas, isto não lhe tira a importância, pois verificamos que a AGROMATE foi uma das fundadoras da OCEPAR em 1971, como consta em ata, e que seu presidente, Benedito Moreira,ocupou um cargo na diretoria da entidade de representação nacional, a UNASCO - União Nacional das Associações Cooperativas, na gestão de 1965.

Portanto, há alguns indícios de organização de um grupo de cooperativas em busca de ação coletiva, mesmo que para este tipo de cooperativas a maior motivação tenha sido uma estratégia para a defesa de sua situação econômica muito adversa.

Para a legislação que na época regulamentava as cooperativas (art. 37, do Decreto-lei no 22.239, de 1932), a federação de cooperativas era uma instituição que só admitia como sócios as cooperativas da mesma espécie e tipo e que tinha as seguintes finalidades: organizar em comum os serviços das cooperativas federadas ou fruir outras vantagens; regular as transferências de associados; permitir, em casos especiais, que os associados de uma cooperativa federada se utilizassem dos serviços de outra também federada; e manter um serviço de assistência técnica e contábil, bem como de inspeção da gestão das cooperativas federadas (ARAÚJO, 1980, p. 65).

Todavia, não foram encontradas provas expressas de ação política propriamente dita, apenas sinais da motivação de um

\footnotetext{
${ }^{24}$ A grave crise no setor deixou marcas que fizeram com que os médios e pequenos produtores de erva mate tivessem que se agrupar, haja vista que de 1926 à 1935 houve uma queda de $30 \%$ da produção de mate no Paraná, crise que se avolumou nos anos seguintes (ARAÚJ0, 1098, p. 63).

25 David Thiessen nasceu em 1935 efoi advogado e assessor da UCEPAR de 1965 até 1971. Entrevista concedida em 28 de abril de 2014. Thiessen foi responsável, juntamente com o ex-presidente da UCEPAR, Keimpe van der Meer de 1961 a 1971, pela ação política direta desta entidade.
} 
agrupamento de cooperativas, em forma federativa e verticalizada, com fins de representação das cooperativas e dos cooperados de erva-mate do Paraná.

No entanto, se não encontramos nas décadas de 1940 e 1950 sinais de ação política coletiva de todos os setores das cooperativas rurais, e considerando a inexistência de uma entidade privada específica para tal ação, não se pode seguramente afirmar que não havia reunião de cooperativas ou dirigentes, buscando uma organização do movimento cooperativista, principalmente após a segunda metade da década de $1950^{26}$.

Esta década foi relevante para o cooperativismo paranaense pela implementação de dois importantes núcleos de cooperativas: (i) as formadas por imigrantes que atuavam com leite e carnes27; e (ii) aquelas que davam início ao movimento formador das cooperativas de café, em 1952 (ARAÚJO, 1980: 67-71)28.

A tese de que ocorreu uma reunião de grupos de cooperativas e de seus dirigentes, mesmo que sem uma entidade representativa formal, baseia-se também no fato de que, em 1944,na cidade de São Paulo, houve o $1^{\circ}$ Congresso de Cooperativismo 29 . Mesmo ocorrendo fora do Paraná, entendemos que não se inviabilizou a participação de paranaenses no evento, considerando que o organizador do encontro foi o Governo de São Paulo ${ }^{30}$. Devemos entender que as sociedades cooperativas desde 1938 eram sociedades tuteladas pelo Estado, isto é, para que uma cooperativa fosse constituída necessitava de autorização expressa, diferentemente dos outros tipos societários. 0 Estado brasileiro estava bem aparelhado

26 Como vimos acima, por movimento cooperativista entende-se o conjunto de pessoas e cooperativas, bem como das entidades representativas, todo o conjunto de princípios norteadores da cooperação (doutrina) bem como o escopo social de igualdade e solidariedade (filosofia).

27 Colônia Carambeí (Cooperativa Batavo - agosto, 1941), Colônia Entre Rios (Cooperativa Agraria - maio, 1951), Colônia Castro (Cooperativa Castrolanda outubro, 1951), Colônia Witmarsum (Cooperativa Wittmarsum - outubro, 1952)(ARAÚJO, 1980, p. 66 e ss.).

28 Também houve o início das cooperativas de café a partir de 1952. De 1957 a 1964, haviam registradas na Junta Comercial do Paraná trinta e novecooperativas de cafeicultores (ARAÚJO, 1980: 71).

29 Centenário de comemoração da fundação da $1^{\text {o }}$ cooperativa moderna, em Rochdale, Inglaterra, em 1844. Detalhes ver Anais do Congresso (SÃO PAULO, 1944)

30 Departamento de Assistência ao Cooperativismo (DAC) da Secretaria da Agricultura, Indústria e Comércio de São Paulo, departamento responsável pela divulgação, ensino, assistência e defesa do cooperativismo e prestação de serviços técnicos, (SÃO PAULO, 1944). 
para exercer o controle e a fiscalização sobre as cooperativas e os cooperados $^{31}$.

Desta forma, muito provavelmente a notícia ou mesmo o incentivo ea repercussãodo $1^{o}$ Congressose estendeu para fora das fronteiras de São Paulo. A relevância está no fato e não na iniciativa pública ou privada, poisse criavaum espaço para reunião e discussão de problemas dos cooperativistas. Há sinais de que durante este congresso se constituíram diversas comissões técnicas para discutir a organização das cooperativas e o "movimento cooperativista" (MOURA, 1991: p. 405).

A proximidade intensa do cooperativismo com o Poder Público, tanto através do controle como do incentivo econômico ${ }^{32}$, aliado ao progresso, em número de cooperativas e de envolvidos, segundo David Thiessen, fez surgir a necessidade da criação de "interlocutores", das cooperativas com o Estado. Uma prova disto é a ideia de criação de uma estrutura de associações de cooperativas, sendo a primeira delas a União das Cooperativas de São Paulo (UCESP) em 195233, e, em 1956, de uma entidade representativa nacional, a União Nacional das Associações Cooperativas (UNASCO). A UNASCO foi fundamental para a construção de uma representação institucional do cooperativismo empresarial, dado que sua meta era a criação de associações filiadas em cada estado da federação ${ }^{34}$.

\footnotetext{
31 Desde o Decreto no 6.980 de 1941, o Poder Executivo Federal, através do Serviço de Economia Rural (SER) do Ministério da Agricultura, era o responsável pela concessão da "Autorização de Funcionamento" das cooperativas. Através de um convênio, suas atividades eram realizadas com apoio dos DAC nos estados. O SER foi extinto, originando o Instituto Nacional de Desenvolvimento agrário (INDA) e mais tarde o Instituto Nacional de Colonização e Reforma Agrária (INCRA), até esta tutela ser extinta pela Constituição Federal de 1988. Sobre a dimensão doutrinária, ver a explicação dada pela Aliança Cooperativa Internacional (ACI), que elenca um conjunto de sete princípios e faz considerações filosóficas para diferenciar as cooperativas dos outros tipos societários (http://ica.coop/en/whats-co-op/cooperative-identity-values-principles).

32 O interesse do Estado no cooperativismo é demonstrado não apenas pelo envolvimento de muitos órgãos estatais, como também por financiamentos, planos de safras agrícolas e preço mínimo para a agricultura, que sempre estiveram nos programas de governo (cf. IPARDES, 1974: cap. XIII).

33 Na década de 1950, São Paulo foi o centro organizado do cooperativismo, fato compreensível naturalmente pela posição, frente a outros centros urbanos, em relação à dinâmica populacional e econômica.

34 Esta idéia foi corroborada por Américo Utumi, advogado, que foi dirigente da Cooperativa COTIA de São Paulo, um dos líderes na criação da Organização das Cooperativas Brasileiras (OCB) e que participou da Aliança Brasileira de Cooperativas (ABCOOP). Hoje Utumi ocupa relevante cargo na ACI Américas. Entrevista realizada em 2014.
} 
Com a constituição da UNASCO, podemos estabelecer a gênese formal do processo organizado e institucional de ação política nacional de um grupo social, os cooperados, e de sua elite política e representativa, os dirigentes das cooperativas. A partir e através da UNASCO, a ação política do cooperativismo passou a ser levada a cabo pelos dirigentes das cooperativas, cujaprática econômica se aproximava cada vez mais da lógica empresarial, no sentido que aqui estamos propondo. Por sua vez, sua ação política os aproximava daquela dos dirigentes de entidades sindicais e associativas de representação empresarial. Daí a sua correlação com a questão do empresariado e da representação empresarial. Como vimos acima, é neste sentido que utilizamos as expressões empresarial, empresário, e seu coletivo, o empresariado, para definir os dirigentes de cooperativas, mesmo cientes da particularidade do uso desta expressão.

Em suma, no período de 1956 a 1971, encontramos a gênese da ação política organizada do cooperativismo no Paraná. Todavia, isso se deu efetivamente apenas em 1965, pois, no Paraná, diferentemente de São Paulo, onde a partir da década de 1950 já há uma estrutura formal de representação e ação política das cooperativas, não havia qualquer estrutura institucional, a não ser a AGROMATE de 1939, da qual não há indícios de ação política.

Entretanto, a década de 1950 foi marcada tanto pelo acréscimo no número de cooperativas, quanto pela formação de agrupamentos organizados em torno de interesses ou afinidades, facilitando entendimentos e reuniões. Segundo David Thiessen, as cooperativas coloniais de alemães e holandeses, localizadas no centrosul do Paraná, já buscavam entendimentos para maior aproximação, visando intercâmbios e a resolução de problemas em comum.

Houve também a reunião dos cafeicultores, que segundo David Thiessen, mesmo reunidos com a finalidade de constituição de cooperativas para atuar junto ao Instituto Brasileiro do Café (política do café e de sua armazenagem), possuía maior proximidade e afinidade com os paulistas, serão partícipes da criação da OCEPAR ${ }^{35}$.

Entendemos, no entanto, que a efetiva ação política do cooperativismo no Paraná somente se dá a partir do início da década

35 Esta proximidade verificada nas lideranças dos cafeicultores com São Paulo, mesmo as cooperativas integrando a UCEPAR, segundo Thiessen, fazia com que as ações deste grupo na UCEPAR fossem mais isoladas, unindo-se apenas em algumas questões gerais, como foi um caso relativo à tributação em 1966. Enfim, este grupo possuía uma ligação maior com São Paulo. 
de 1960, haja vista a pulverização do setor em pequenas cooperativas distribuídas em várias regiões do Estado (ARAÚJO, 1980: 65) ${ }^{36}$.

A UCEPAR - União das Cooperativas do Paraná foi criada em janeiro de 1965, segundo um relatório da UNASCO deste ano, para ser a entidade de representação política das cooperativas no Paraná. Sua criação foi fruto do esforço da própria UNASCO, leia-se UCESP, através da liderança de Francisco Toledo Piza ${ }^{37}$. A UNASCO teve influência decisiva na reunião de grupos de cooperativistas paranaenses, principalmente, aqueles já existentes, ligados às cooperativas de leite e carnes, capitaneados pelos holandeses e alemães no Paraná, que já se reuniam desde 1961, segundo David Thiessen, para resoluções de problemas em comum. A UCEPAR foi se formando com a união de grupos de diversas localidades e com diferentes produtos dentro de atividades econômicas agrícolas entre outras. Destacando-se três grupos: (i) produtores de erva-mate do sul do Paraná; (ii) cooperativas de leite e carne da região centro-sul (alemães e holandeses); (iii) cooperativas de cafeicultores, no norte do estado.

Havia poucas pessoas envolvidas com o cooperativismo e as lideranças eram, portanto, ainda mais raras, segundo Tadeu Duda ${ }^{38}$. Segundo David Thiessen, talvez por isso a UCEPAR "nasceu pequena e se extinguiu pequena". Desta forma, podemos estabelecer o ano de 1965 como sendo o momento da gênese da ação política organizada do cooperativismo rural no Paraná.

Em 1969, com a criação da Organização das Cooperativas Brasileiras (OCB) ${ }^{39}$, entidade nacional resultante da junção das duas entidades nacionais de representação do cooperativismo, aUnião Nacional das Associações Cooperativas (UNASCO) e a Aliança Brasileira

36 No setor de produção de grãos há apenas a cultura de subsistência ou parca comercialização, e a abrangênciade várias culturas, desde batata, leite, trigo, cana, madeireira e erva mate até o início do café. Se analisada do ponto de vista de produção econômica e do pessoal envolvido, chega-se a números que demonstram uma quase inexpressão (IPARDES, 1974: cap. II).

37 Advogado paulistano e dirigente de cooperativa de consumo, oriundo de importante família paulista foi o presidente e principal líder do grupo que constituiu a UNASCO até sua extinção em 1969. Informação fornecida por Américo Utumi.

38 O senhor Tadeu Duda foi funcionário público do INCRA e auxilio diretamente a constituição da OCEPAR, tendo sido o primeiro empregado desta entidade.

${ }^{39}$ Ao tratar da relação entre Estado e entidades representativas do empresariado rural nos anos 1980, Sonia Mendonça destaca a Sociedade Rural Brasileira e a OCB, sendo esta a "nova força emergente na disputa pela hegemonia patronal", e representante dos segmentos mais "modernizados" ou "empresarializados" da agricultura (aspas da autora) (MENDONÇA, 2010, pp. 70 e 71). 
de Cooperativas (ABCOOP), a ação política do cooperativismo brasileiro passou a ser realizada de forma unitária ${ }^{40}$.

No Paraná, bem como nos outros estados da federação, as lideranças nacionais começaram um processo de aglutinação e conscientização da necessidade de criação de organizações estaduais (OCB, 2004: 45-47), em substituição às filiadas da UNASCO e ABCOOP41. Em 1970, trinta e oito cooperativas redigiram e subscreveram um documento intitulado de "Apelo Urgente" que impulsionou a formalização da nova entidade de representação estadual do cooperativismo paranaense, filiada a OCB. Deste processo resultou a criação da OCEPAR - Organização das Cooperativas do Estado do Paraná em 1971, sucedendo a UCEPAR, que se extinguiu.

Em suma, foino período de 1941 a 1956 que se formou a base para a institucionalização da ação política do cooperativismo empresarial: (i) o início das reuniões de grupos de cooperativas; (ii) o surgimento da entidade de representação nacional (UNASCO); (iii) o aumento do número de cooperativas com certa identidade, possibilitando a aproximação através dos interesses mais comuns, como aconteceu com os imigrantes alemães e holandeses e com os cafeicultores; e (iv) com o fim da ditadura Vargas em 1945.

Cabe aqui ao menos mencionar a semelhança com o que aconteceu com a forma sindical de representação sindical ${ }^{42}$. Ou seja, entendemos que o período democrático que se inicia em 1946 não foi somente um mero momento histórico, mas sim um pano de fundo e um dos fatores de fomento à complexificação e à institucionalização das formas de representação das cooperativas empresariais. Ou seja, o contexto democrático favorecia a organização e o estabelecimento de relações com o poder público, que antes eram limitadas pela natureza autoritária do regime político do Estado Novo, fazendo com que o cooperativismo ao mesmo tempo se beneficiasse quanto favorecesse a democracia.

Mas, se a democracia de 1946 a 1964 marcou todo o processo de institucionalização e efetivação da ação política do

40 Em 1965, conflitos ideológicos dentro da UNASCO, leia-se, entre as lideranças paulistas, deram origem a uma nova entidade de representação nacional, a ABCOOP. Em 1969, por influência do Ministro da Agricultura Cirne Lima, houve a junção das duas entidades para criação da OCB (OCB, 2014: 43).

${ }^{41}$ Quanto ao Paraná, em termos de atuação representativa organizada, apontamos apenas a UCEPAR (filiada a UNASCO). Quanto à ABCOOP, segundo David Thiessen, não há registros de qualquer filiada sua no Paraná.

42 Sobre a relação entre as formas sindicais de representação empresarial, em geral chamada de corporativismo, e a democracia de 1946-1964, ver Costa (1998). 
cooperativismo, não se pode desconsiderar certa continuidade com os momentos anteriores e posteriores, ou seja, a forte presença do Estado.

Em relação a este aspecto há que se considerar que o Estado sempre manteve o seu papel de organizador e regulador das formas cooperativas. Assim, da mesma forma que no sindicalismo de trabalhadores e empresários, a influência da tutela estatal no cooperativismo também foi um fator de grande influência na institucionalização da ação política do setor. Na década de 1940, a realidade da atividade econômica produtiva era bastante particular e a agricultura se dividia entre os grandes produtores e latifundiários e os pequenos produtores. A tendência do Estado em controlar o cooperativismo é demonstrada pelo interesse e apoio de diversos órgãos governamentais, através de financiamentos, planos de safras agrícolas, preço mínimo para a agricultura, presentes nos programas de governo. Esta hipertrofia do Estado na iniciativa privada do cooperativismo agrícola verifica-se inclusive no fato de que só encontramos dados sobre o setor cooperativista agropecuário antes de 1970 nos estudos econômicos produzidos pelo próprio Estado 43 .

Esta relação dual e ambivalente do Estado, agindo ora como ente fiscalizador, ora como ente incentivador de cooperativas fortes e atuantes do ponto de vista econômico, aliado ao crescimento do setor em número de cooperativas e em importância, tanto econômica como mecanismo de controle social, trouxe um conflito de identidade ${ }^{44}$. Mas, ao mesmo tempo, isso foi decisivo para a existência do que aqui estamos chamando de cooperativismo empresarial e das suas formas de ação política. A promoção de incentivos e auxílios à formação de cooperativas formou uma categoria econômica detectável já em 1940, pelo menos, de forma pioneira, em São Paulo.

Nas décadas de 1940 e 1960 a atuação do Estado se deu através do Departamento de Assistência ao Cooperativismo. Esta ação do DAC se manifestou na organização do $1^{\circ}$ Congresso em 1944, com o objetivo de reunir as lideranças das cooperativas, e a edição desde 1940 de um boletim mensal sobre cooperativismo, incentivando a prática das cooperativas e a reunião de dirigentes, mesmo sem a existência de uma entidade representativa privada.

Mesmo com a criação da União Nacional das Associações Cooperativas (UNASCO) em 1956, ou seja, de uma entidade representativa privada constituída por lideranças aptas a realizar ação

43 Em documento do IPARDES são citados todos os diversos órgãos que interferem nas cooperativas e nas suas funções (IPARDES 1974, cap. XIII).

${ }^{44}$ Segundo Araújo, esse foi o caso da crise da erva-mate em 1930 (ARAÚJO, 1981, p. 62-66). 
política em prol do grupo que representa, é certo que em qualquer relação formal, o simples fato de uma das partes possuir a prerrogativa legal de autorizar, fiscalizar e confiscar o registro, enfim, a possibilidade de findar a existência legal de uma cooperativa, além da capacidade de criar incentivos e políticas, foi um fator que moldou o relacionamento e influencioua atuação das entidades representativas, bem como a organização de uma elite político-representativa, composta pelos dirigentes de cooperativas empresariais.

Enfim, constatamos que a institucionalização da representação do cooperativismo empresarial paranaensese consolidou em 1965, com a criação da UCEPAR. Embora, cronologicamente, isso tenha se dado já no quadro do regime autoritário do pós-1964, foi gestado ainda no período da democracia de 1946-1964. A gestação deste processo, mesmo que tímido e com pouca expressão, se deu na década de 1950. Portanto, ocorreuno Paraná algo semelhante ao que se deu em âmbito nacional, ou mais particularmente em São Paulo, que até este momento, era o centro mais importante do cooperativismo agropecuário no Brasil, posição que veio a ser assumida pelo Paraná aproximadamente a partir dos anos 1980. Mas isso não permite desconsiderar que no Paraná a dimensão estatal se mostrou tão incisiva quanto a democracia. A seguir, veremos as particularidades deste processo.

\section{II - Da UCEPAR à OCEPAR}

A situação da época em que foi idealizada a UCEPAR era de isolamento das cooperativas e de pouca expressão econômica do setor, segundo David Thiessen. No entanto, a existência da UCEPAR, segundo as palavras de seu ex-presidente Keimpe van der Meer, foi fundamental como gênese de uma união das cooperativas. Segundo Meer, isso se deu ao longo do tempo, através de um "movimento lento, mas regular" e que se consolidou 45 .

Com uma existência apenas informal, dado que seu estatuto nunca foi registrado em qualquer órgão oficial, e funcionando em um pequeno escritório emprestado em Curitiba, a ação política da UCEPAR se concentrava em atuar em torno das dificuldades do setor cooperativista e das atividades econômicas dos associados. Uma particularidade a se destacar era a questão partidária. A UCEPAR possuía uma cláusula em seu estatuto acerca de uma neutralidade

\footnotetext{
${ }^{45}$ Esta informação foi obtida em entrevista com Keimpe van der Meer, realizada em 04 de fevereiro de 1989 pela OCEPAR para construção de um memorial histórico da instituição.
} 
política, que pode ser entendida por neutralidade partidária. Assim, tanto as ações antes de 1964 quanto as ações após 1965 não eram dirigidas à estrutura de Estado e sim a questões setoriais econômicas, tributárias e regulamentares das cooperativas, segundo David Thiessen.

A partir de sua criação, destacam-se duas relevantes ações políticas da UCEPAR. A primeira visou a alteração do antigo tributo de circulação de mercadorias, o Imposto sobre Vendas e Consignações (IVC), o que veio a acontecer em 1966. A UCEPAR conseguiu apoio político para alterar o curso da tributação estadual, através do Poder Legislativo Estadual, no entanto houve veto deste dispositivo legal pelo então governador Paulo Pimentel. Após este malogro, a UCEPAR mobilizou lideranças das cooperativas e em audiência com o governador conseguiu a revogação do veto eliminando as distorções do IVC que prejudicavam as cooperativas.

Segundo David Thiessen, em 1967, um dos feitos da UCEPAR que renderam frutos posteriormente foi o agendamento de uma reunião entre o presidente da UNASCO, o paulista Francisco Piza, com o recém indicado Ministro da Agricultura, o paranaense Ivo Arzua. A pauta era a solicitação de uma política agrícola que não prejudicasse as cooperativas. Como houve uma boa recepção do Ministro às reivindicações da UNASCO, foi feito também um pedido para indicação de preenchimento de cargo junto ao Banco Nacional de Crédito Cooperativo, que foi concedido ${ }^{46}$. Esta proximidade ajudou em interlocuções futuras para a oitiva do setor quando da elaboração, pelo governo, da lei cooperativista de 1971.

A extinção da UNASCO e criação da OCEPAR não foi um processo traumático ou de cisão entre as cooperativas, na afirmação de Tadeu Duda, David Thiessen e Wilson Thiesen ${ }^{47}$. Houve um grande apoio e incentivo do Estado através do INCRA para a formação da OCEPAR, com participação de todas as cooperativas do Paraná, mesmo porque a legislação (Lei Federal no 5.764/71) ${ }^{48}$ determinava registro compulsório como condição de funcionamento, havendo ainda a tutela estatal, que só se extinguiria com a Constituição Federal de 1988.

46 O BNCC - Banco Nacional de Crédito Cooperativo era a instituição financeira responsável pelo apoio econômico (empréstimos) para as cooperativas.

47 Wilson Thiesen foi secretário da comissão que criou a OCEPAR, na condição de funcionário do INCRA e mais tarde assumiu a presidência da OCEPAR (1987-1989) e da OCB (1991-1994).

${ }^{48}$ Art. 107. - As cooperativas são obrigadas, para seu funcionamento, a registrar-se na Organização das Cooperativas Brasileiras ou na entidade estadual, se houver, mediante apresentação dos estatutos sociais e suas alterações posteriores. 
Decorrem da análise deste período os seguintes aspectos: (i) a existência de duas entidades privadas nacionais de representação política do cooperativismo e correspondente ação política nacional, a partir da década de 1950 (UNASCO e ABCOOP); (ii) a inexistência de uma afiliada paranaense no Paraná da ABCOOP; (iii) a existência de representação política da UCEPAR, filiada paranaense da UNASCO, com ação política no Paraná na segunda metade da década de 1960; (iv) uma alteração do panorama político representativo dual do cooperativismo em 1969, pela "união" e consequente extinção da UNASCO e ABCOOP que resultou na criação de uma única entidade nacional de representação política do cooperativismo a OCB Organização das Cooperativas Brasileiras, com obrigatoriedade de pertença, através de registro compulsório instituído por lei; (v) a criação da OCEPAR em 1971, sucedendo a UCEPAR.

Em suma, considerando que estamos entendendo por ação política institucionalizada a existência de entidade específica e criada para esta finalidade, concluímos que só a partir de 1940 há sinais da ocorrência de reunião organizada de lideranças do cooperativismo, como é o caso da federação do mate, a AGROMATE, cujo setor, mesmo em declínio, foi importante até anos 1970. Mas foi a partir de 1950, com as reuniões de cooperativas coloniais (holandeses e alemães), que surgiu a UCEPAR (União das Cooperativas do Paraná).

Nas décadas de 1960 e 1970, em um ambiente setorial cuja formação era de pequena expressão econômica e pouca representatividade populacional, qualquer movimento de união política organizada fazia efeito e foi a união em torno da UCEPAR a responsável por todas as conquistas do setor cooperativista paranaense junto ao Estado, segundo David Thiessen. Também a existência de um agrupamento de líderes foi a estrutura facilitadora e possível para a instalação de ambiente para a criação no Paraná, da entidade de representação política e única, determinada pela lei das cooperativas em 1971.

Portanto, a criação da OCEPAR só foi possível devido à existência e à função política iniciada pela UCEPAR. Deste modo, apesar dos limites nas suas atividades e na sua ação política, A UCEPAR foi o embrião tanto da formalização de ação política do setor cooperativista agropecuário paranaense, quanto da existência da OCEPAR enquanto entidade representativa dos dirigentes de cooperativas, que aqui estamos chamando de empresariais. Neste aspecto, o Paraná se distingue dos outros estados, inclusive São Paulo. 


\section{III - Considerações finais}

Verificamos que as características do processo de constituição da representação política do cooperativismo rural no Paraná remetem a um processo mais amplo de constituição legal e organizacional do cooperativismo no Brasil. Além disso, o caso do cooperativismo rural paranaense mostra como isso, entre outras características, implica tanto na constituição de um importante agente econômico que tem que assumir uma lógica de gerenciamento empresarial, quanto uma forma de representação política do empresariado.

Neste sentido verificamos alguns aspectos que nos parecem fundamentais. Em primeiro lugar, o caso do Paraná mostra o peso da atuação do Estado, nos âmbitos estadual e federal, no controle do cooperativismo, desde o incentivo à criação das entidades, passando pela orientação do seu funcionamento, até a sua fiscalização. Em segundo lugar, esta atuação do Estado estimulou e favoreceu o surgimento das cooperativas empresariais, (economicamente viáveis) além de impactar sobre a institucionalização de sua ação política.

Em terceiro lugar, o Estado influenciou também a formação da elite político-representativa, moldando-a para interlocução. Esta é uma das agendas de pesquisa que se colocam para futuros estudos. $\mathrm{Ou}$ seja, a análise do recrutamento, das características e do comportamento dos altos dirigentes das cooperativas empresariais e dos dirigentes de suas organizações. Trata-se de uma elite que deve ter não só a capacidade de promover os interesses dos associados, como possuir competências gerenciais diferenciadas e assumir a representação política. Neste sentido, noções como a de elite empresarial teriam que ser adaptadas a estas particularidades ${ }^{49}$. 0 mesmo ocorreria com o eventual uso de outros conceitos como os de elite econômica e de classe social. Isso tudo remete à necessidade de construção de novas e específicas categorias analíticas, nos âmbitos teórico e metodológico, para a análise sociológica do fenômeno do cooperativismo empresarial, bem como da recorrência a comparações com sua eventual manifestação em outras sociedades.

Por exemplo, podemos mencionar a proposição de Offee Wisentahl de que, enquanto o trabalhador possui uma, o capital possui três formas de ação coletiva para definição e defesa de seus interesses, a própria "firma", a cooperação informal e a associação de empregadores (OFFE e WIESENTAHL, 1984, p. 66). Ressalvada a natureza desta reflexão, tal proposição não dá conta das

\footnotetext{
${ }^{49}$ Sobre esta noção, ver Costa 2012 a e 2012b.
} 
particularidades de um fenômeno, por excelência capitalista, que é a cooperativa empresarial. Essa possui aspectos de uma firma, a qual se baseia em uma forma em essência baseada na cooperação entre pequenos produtores, assume o processo de representação e ação políticade interesses e não deixa de ser também uma associação empresarial que também se relaciona com os trabalhadores.

E será que o teste das hipóteses levantadas por Olson (1999), no sentido de verificar se, historicamente, o fenômeno das cooperativas empresariais decorreu de incentivos ou de formas de coerção daria conta de todas as suas particularidades?

E no que diz respeito ao processo de institucionalização da representação política dos grupos sociais no Brasil, há que se explorar a análise das semelhanças e diferenças do cooperativismo empresarial em relação às formas sindicais e associativas de representação empresarial. A cooperativa empresarial é diferente do sindicato de trabalhadores, pois não diz respeito a assalariados e possui uma natureza econômicade cunho societário e tem que agir como uma empresa. Mas, tem também uma dimensão sindical, no sentido da representação formal, legal, de seus associados.

Assim como na clássica questão do corporativismo no Brasil, há que se verificar o quanto os cooperados interferiram na legislação que permitiu a existência e regulou o funcionamento das cooperativas, em especial a sua forma empresarial. Ou seja, não há porque considerar tanto o corporativismo quanto o cooperativismo como processos unilateralmente definidos pelo Estado, mesmo que sejam regulados por leis específicas.

Em suma, os objetivos fundamentais deste trabalho foram o de contribuir para a compreensão deste complexo fenômeno que é o cooperativismo no Brasil e o de chamar a atenção dos pesquisadores para as particularidades e a relevância do tema das cooperativas empresariais para os estudos sobre a política, a sociedade e a economia do Brasil.

\section{Referências}

ARAÚJO, Sílvia Maria Pereira de. O Cooperativismo Agrícola Paranaense, segundo os arquivos da Junta Comercial do Paraná (1916-1976). In: PARANÁ. Banco de Desenvolvimento do Paraná S/S. Revista Paranaense de Desenvolvimento. Curitiba, no 70, janeiro/fevereiro/março, 77p, 1980. 
BELUSSO, D. Associados e integrados: a face híbrida do cooperativismo empresarial no campo. Revista RA' E GA, n. 13, p. 59-64, Curitiba, Editora da Ufpr, 2007.

BEN, M. e SCHLOSSER, M. T. S. A territorialização do cooperativismo empresarial no oeste paranaense. Revista Pegada - vol. 13 n.2, dezembro, 2012.

BENETTI, M. D. Origem e formação do cooperativismo empresarial no Rio Grande do Sul: uma análise do desenvolvimento da COTRIJUI, COTRISA e FECOTRIGO - 1957/1980. Tese de Doutorado. FEE, Rio Grande do Sul, 1992.

BOESCHE, Leonardo. Fidelidade Cooperativa - uma abordagem prática. Curitiba: Sescoop-PR, 2005.

BULGARELLI, Waldírio. Regime jurídico das sociedades cooperativas. São Paulo: Pioneira, 1965.

CARnEIR0, Palmyos Paixão. A Cooperação. Belo Horizonte: UNIMED-BH, 1983.

CORADINI, O. L. e FREDERICQ, A. Agricultura, cooperativas e multinacionais. Rio de Janeiro, Centro Edelstein de Pesquisas Sociais, 2009.

COSTA, Paulo Roberto Neves. Democracia nos anos 1950: burguesia, corporativismo e parlamento. São Paulo, Hucitec, 1998.

COSTA, Paulo Roberto Neves. A elite empresarial e as instituições democráticas: cultura política, confiança e padrões de ação política. Opinião Pública. Campinas, v. 18, n. 2, Novembro, 2012a.

COSTA, Paulo Roberto Neves. A Elite Empresarial - Teoria e Método na Análise da Relação entre o Empresariado e Democracia. Trabalho publicado por ocasião do 36ํㅡㄹ Encontro Anual da ANPOCS - GT36 - Grupos de dirigentes e estruturas de poder. 37p., 2012b.

DONADONE, Júlio César; SILVEIRA, Frederico Zenorini da e RALIO, Vanise Rafaela Zivieri. Consultoria para pequenas e médias empresas: as formas de atuação e configuração no espaço de consultoria brasileiro. Gestão da Produção. vol.19, n.1, 2012.

FERnANDEZ, Jose M. Ciurana. Curso de Cooperacion. Barcelona: Bosch, Casa Editorial, 1968.

FILHO LUZ, Fábio. 0 direito cooperativo. Rio de Janeiro: Irmãos Pongetti Editores, 1962.

FRANKE, Walmor. Direito das sociedades cooperativas. São Paulo: Saraiva; EdUsp, 1973. 
IPARDES. Cooperativas de Produção Agropecuária do Estado do Paraná. Diagnóstico e Análises. Curitiba, 1974.

JOHANNES, U. Apresentação. In: UTUMI, Américo; PINHO, Carlos Marques; PINHO, Diva Benevides, et al. A Problemática cooperativista no desenvolvimento econômico. Coletânea publicada com a colaboração da Fundação Friedrich Naumann, Bonn - Bad Godesberg. Alemanha. Artegráfica: São Paulo. p. 7-13, 1973.

KIEWIET, Ruth; KIEWIET, Willem. Imigrantes - Immigranten. História da Imigração holandesa na região dos Campos Gerais, 1911-2011. A Colônia de Gonçalves Júnior - Irati - PR: A imigração holandesa de 1908 - 1909 no Brasil. Carambeí: Estúdio Texto / APHC Editorial / NMC - Núcleo de Mídia e Conhecimento, 2011. Disponível em: http://aphc.com.br/wpcontent/uploads/2011/12/Livro-Gon\%C3\%A7alves-Jr.pdf. Acesso em $12 / 05 / 2014$.

LAIDLAW, A.F. As Cooperativas no ano 2000. Relatório da Aliança Cooperativa Internacional - ACI, apresentado no XXVII Congresso de Moscou, 1980. Coleção Ato Cooperativo - Org. das Coop. de Minas Gerais OCEMG. Belo Horizonte, 1980.

LAVILLE, Jean-Louis. Economia solidária, a perspectiva européia. Sociedade e Estado, vol.16, n.1-2, 2001.

MENDONÇA, S. R. de. O patronato rural no Brasil recente (1964-1993). Rio de Janeiro, Editora da UFRJ, 2010.

MERIGHI, Cristiane de C.; LIMA, Terezinha Bazé de; ALBUQUERQUE, Fabrício Bazé de e ORMED0, Rosana. Estudos do comportamento da liderança na Cooperativa de Crédito Rural Centro Norte do Mato Grosso do Sul, unidade Chapadão do Sul, como fator de desenvolvimento local. Interações (Campo Grande), vol.14, n.2, 2013.

MOURA, V.; PINHO, D. B., et al.As Grandes Coordenadas da Memória do Cooperativismo Brasileiro.Brasília, OCB/Coopercultura, Vol. I, p.404-417, 1991.

NUNES, Christiane Girard Ferreira. Cooperativas: uma possível transformação identitária para os trabalhadores do setor informal? Sociedade e Estado, vol.16, 2001.

OCB. Organização das Cooperativas Brasileiras. Cooperativismo brasileiro: uma história. São Paulo, 2004.

OCEPAR. Ações de Responsabilidade Social do Cooperativismo Paranaense. Revista Paraná Cooperativo, Edição Especial. Curitiba, 155p, 2013.

OCEPAR. Associação de orientação às cooperativas. Relatório: III Encontro de Dirigentes Cooperativistas. Curitiba, 1971. 
OFFE, C. e WIESENTAHL, H. Duas lógicas da ação coletiva: anotações teóricas sobre classe social e Forma Organizacional. In: C. OFFE. Problemas estruturais do Estado capitalista. Rio de Janeiro, Tempo Brasileiro, 1984.

OLSON, M. A lógica da ação coletiva. São Paulo, EDUSP, 1999.

PINHO, D. B. (Org.). As Grandes Coordenadas da Memória do Cooperativismo no Brasil. Brasília, OCB/Coopercultura, Vol. I e II, 1991.

RODRIGUES, R. L. e GUILHOTO, J. J. M. Estrutura produtiva, relações intersetoriais e cooperativas agropecuárias no Paraná em 1980 e 1985. Revista de Economia e Sociologia Rural, vol. 42, n. 2, p. 243-266, 2004.

SÃO PAULO. Secretaria da Agricultura, Indústria e Comércio. Boletim do Departamento de Assistência ao Cooperativismo. Anais do Io Congresso Brasileiro de Cooperativismo - 1944. Suplemento Ilustrado, Dez., ano V, no 51, São Paulo, 1944.

SIMIONI, F. J. et al. Lealdade e oportunismo nas cooperativas: desafios e mudanças na gestão. Revista de Economia e Sociologia Rural, vol.47, n.3, 2009.

SINGER, P. Economia solidária versus economia capitalista. Sociedade e estado, vol.16, n.1-2, 2001.

SOUZA, U.R. de; BRAGA, M. J.e FERREIRA, M. A. M. Fatores associados à eficiência técnica e de escala das cooperativas agropecuárias paranaenses. Revista de Economia e Sociologia Rural, vol.49, n.3, 2011.

STADUTO, J. A. R.; ROCHA JR, Weimar F. e BITENCOURT, Mayra B. Contratos no mercado de trabalho agrícola: o caso das cooperativas de trabalhadores rurais. Revista de Economia e Sociologia Rural, vol.42, n.4, 2004.

Entrevistas:

Américo Utumi (realizada em 2014)

David Thiessen (realizada em 2014)

Keimpe van der Meer (realizada em 1989)

Tadeu Duda (realizada em 2014)

Wilson Thiesen (realizadaem 2014)

Recebido em 29 de julho de 2014

Aprovado em 30 de março de 2015 


\title{
Cooperatives and corporate political representation in Brazil: the case of rural cooperativism in Paraná
}

\begin{abstract}
This article analyses the genesis of rural cooperatives' political action institutionalization process in Paraná state, in order to study it as a way of corporate political representation in Brazil. Using documents and interviews, the research covered the period from 1907 to the creation of OCEPAR (Union and Organization of Cooperatives of the State of Paraná) in 1971, one of the most important representative entities of cooperativism in Brazil. This study is important for the analysis of the relationship between cooperatives and business interests in Brazil and particularly in Paraná, and also of the issues which still influence its political action. We note the historical and legal particularities of Brazilian cooperativism and the need to build analytical categories able to deal with the complexity of its corporate dimension.
\end{abstract}

Keywords: businessmen; rural cooperativism; corporate policial representation; OCEPAR; Paraná. 